|| Print ISSN: 2589-7837 || Online ISSN: 2581-3935 || International Journal of Medical Science and Diagnosis Research (IJMSDR)

Available Online at www.ijmsdr.com

NLM (National Library of Medicine ID: 101738824)

\title{
ASSESSMENT OF DIFFERENT TREATMENT PATTERNS IN MIGRAINE WITH CO-MORBIDITIES
}

\section{B. Shravani ${ }^{i^{*}}$, R. Rasmitha ${ }^{1}$, E. Srinivas Rao ${ }^{2}$, A. Gouthami ${ }^{3}$}

${ }^{1^{*}}$ Pharm D Intern, Department of pharmacy practice, Vaagdevi Pharmacy College

${ }^{1}$ Pharm D Intern, Department of pharmacy practice, Vaagdevi Pharmacy College

${ }^{2} \mathrm{MS}, \mathrm{MCH}$, Neurology, Srinivasa Pinnacle, Hanamkonda

${ }^{3}$ Pharm D, Assistant Professor, Vaagdevi Pharmacy College

Conflicts of Interest: Nil

Corresponding Author: B. Shravani

DOI: https://doi.org/10.32553/ijmsdr.v4i9.673

\section{Abstract:}

Objective: To provide effective treatment pattern based on individual patient response, pharmacological and nonpharmacological treatment strategies, effective patient counseling for obtaining adherence to medication.

Methodology: A prospective observational study was conducted in outpatient department of neuro care center for a period of six months.

Results: Out of 1000 patients, Female ratio (86.9\%) was high in age group $31-50$ years (47\%). Non-compliance to medication (21.1\%) was seen which may be the cause for recurrent migraine and response to migraine treatment. We have taken 2 types of treatment patterns which include FPANR and DPANR. In which, FPANR were $85.1 \%$ and DPANR were 14.9\%. Statistical analysis was also done based on chi-square test, odd's ratio, standard deviation. Using chi-square \& odd's ratio statistical analytical methods the values for migraine types were found to be $0.2735 \& 0.8849$ respectively with $95 \%$ confidence interval of value 0.559-1.4. Using chi-square \& odd's ratio statistical analytical methods the values for treatment pattern were found to be $0.1853 \& 0.8954$ respectively with $95 \%$ confidence interval of value $0.54-1.4$.

Conclusion: Female ratio was high compared to male and was significantly high in 31-50 years of age which might be due to skipped breakfasts, fasting, hormonal imbalances, stress. Medication adherence was found to be very low which might be one of the major factors for recurrent episodes of migraine \& response to migraine treatment. Clinical pharmacist plays an important role in treatment and management of headache disorders. They can also provide insight and patient counselling to help prevent or reduce the risk of medication overuse and educating them on medication adherence, triggering factors, and acute treatment.

\section{Introduction:}

Migraine is a benign episodic syndrome of headache associated with other neurological symptoms. Secondary to tension type it is the most common cause of headache affecting approximately $\sim 15 \%$ of women and $6 \%$ of men annually. Classic triad includes

(1) Pre-monitory visual, sensory and motor symptoms

(2) Unilateral throbbing headache

(3) Nausea and Vomiting.

Most of the patients do not have visual aura or other premonitory symptoms, photo and phonophobia are in common. Attacks may be triggered by glare, bright lights, sounds, hunger, stress, physical exertion, hormonal fluctuations, lack of sleep, alcohol, or other chemical stimulation.

Simplified diagnostic criteria for migraine:

\begin{tabular}{ll}
\hline $\begin{array}{l}\text { At least two of the following } \\
\text { features }\end{array}$ & $\begin{array}{l}\text { Plus at least one of the following } \\
\text { features }\end{array}$ \\
\hline Unilateral pain & Nausea or vomiting \\
\hline Throbbing pain & Photophobia or phonophobia \\
\hline Aggravated by movement & \\
\hline Moderate or severe intensity & \\
\hline
\end{tabular}

Treatment pattern: There are 3 approaches to migraine treatment

- Non-Pharmacological (avoidance of patient-specific triggers),

- Pharmacological -Drug treatment of acute attacks (Analgesics, NSAIDS, Triptans)

- Prophylaxis (Beta Blockers, Anti-Depressants, AntiConvulsants)(1)

Establish realistic expectations: When patients are introduced to migraine prophylaxis, they may expect that attacks will cease soon after Starting treatment but most established therapies have treatment latencies. The patient should be involved in the process to help establish individual treatment expectations. Thus, it is crucial that patients understand that any of the following can define success in migraine prevention.

$50 \%$ reduction in the frequency of days with headache or migraine

> Significant decrease in attack duration as defined by patient

$>$ Significant decrease in attack severity as defined by patient 
$>$ Improved response to acute treatment

$>$ Reduction in migraine-related disability and improvements in functioning in important areas of life

$>$ Improvements in health-related quality of life and reduction in psychological distress due to migraine(2)

\section{Materials and methods:}

Data has been collected from outpatient department of a neuro care centre in Hanamkonda. This was a prospective observational study conducted for a period of six months.

Inclusion criteria: All migraine patients including comorbidities were included in the study. Except,

1) Patients with $\mathrm{PAH}$, severe kidney or liver failure.

2) Pregnancy and lactation.

3) Women who are planning to conceive.

4) Age under 12 or above 65.

Source of data for this study was collected from case sheets and detailed history from taken from patients. Drug effectiveness was obtained by the questionnaire,

1) What is the onset of action of a pill?

2) Is pain free after 2 hours?

3) Improvement of headache from moderate or severe to mild or none after 2 hours?

4) Consistent efficacy in 2 or 3 attacks?

5) No headache reoccurrence and no further drug intake within 24 hours after successful treatment (so called sustained pain relief or pain free)?

6) If migraine is recurrent- is it due to medication incompliance or although on regular medication?

7) How many drugs (rizatriptan and naproxen) are taken in a month?

Considered parameters were Age (Young Adult: 12-30 Years, Adult: 31-50 Years, Elderly: 51-65 Years), Gender, Co-Morbidities (HTN, DM, Thyroid, Depression, Anxiety Disorder, Sensory Symptoms, Somatic Symptoms, Seizures, Sinusitis, Stroke), Treatment pattern (FPANR, DPANR), number of Acute medications used in a month, Medication Adherence, Severity of pain, Drug efficacy questionnaire.

\section{RESULTS:}

A total of 1000 patients were selected and their prescription data was analysed.

\section{Table1: Gender wise distribution}

Of total study population, female (86.9\%) were predominant over male (13.1\%).

\begin{tabular}{ll}
\hline GENDER & TOTAL NO. OF PATIENTS \\
\hline FEMALE & $869(86.9 \%)$ \\
\hline MALE & $131(13.1 \%)$ \\
\hline
\end{tabular}

The mean age of our study population was 41.9 years. In our study, the prevalence of migraine is low in early old age people $51-65$ years age group $(23.4 \%$ in which female were $19.9 \%$ \& male were $3.5 \%$ ); $24.1 \%$ (20\% were female
\& $4.1 \%$ were male) in $12-30$ years age group and $52.5 \%$ ( $47 \%$ were female $\& 5.5 \%$ were male) in $31-50$ years.

Table 2: Age wise distribution

\begin{tabular}{llll}
\hline AGE & $\mathbf{1 2 - 3 0}$ & $\mathbf{3 1 - 5 0}$ & $\mathbf{5 1 - 6 5}$ \\
\hline FEMALE & 200 & 470 & 199 \\
& $(20 \%)$ & $(47 \%)$ & $(19.9 \%)$ \\
\hline MALE & 41 & 55 & 35 \\
& $(4.1 \%)$ & $(5.5 \%)$ & $(3.5 \%)$ \\
\hline TOTAL & 241 & 525 & 234 \\
& $(24.1 \%)$ & $(52.6 \%)$ & $(23.4 \%)$ \\
\hline
\end{tabular}

In our study, $41.5 \%$ are with different underlying comorbidities in which stroke were $0.9 \%$, MAV were $1.4 \%$, hypertension were $8.8 \%$, depression were $0.4 \%$, diabetes were $2.6 \%$, epilepsy were $0.9 \%$, thyroid disorder were $1.9 \%$, sinusitis were $0.4 \%$, anxiety disorders were $7.8 \%$ \& somatic symptoms were $16.4 \%$ (LBA were $9 \%$, Hemiparesthesia were

$2.2 \%$, sciatica were $3.5 \%$, neck pain were $0.7 \%$, muscle cramps were $1 \%) \& 58.5 \%$ are with no underlying comorbidities.

Table 3: Co-morbid conditions

\begin{tabular}{llll}
\hline CO-MORBID CONDITIONS & MALE & FEMALE & TOTAL \\
\hline STROKE & 1 & 8 & 9 \\
& $(0.1 \%)$ & $(0.8 \%)$ & $(0.9 \%)$ \\
\hline MAV & 2 & 12 & 14 \\
& $(0.2 \%)$ & $(1.2 \%)$ & $(1.4 \%)$ \\
\hline HYPER & 10 & 78 & 88 \\
TENSION & $(1 \%)$ & $(7.8 \%)$ & $(8.8 \%)$ \\
\hline LBA & 6 & 84 & 90 \\
& $(0.6 \%)$ & $(8.4 \%)$ & $(9 \%)$ \\
\hline HEMI & - & 22 & 22 \\
PARESTHESIA & & $(2.2 \%)$ & $(2.2 \%)$ \\
\hline DEPRESSION & - & 4 & 4 \\
& & $(0.4 \%)$ & $(0.4 \%)$ \\
\hline DIABETES & 4 & 22 & 26 \\
& $(0.4 \%)$ & $(2.2 \%)$ & $(2.6 \%)$ \\
\hline EPILEPSY & 1 & 8 & 9 \\
& $(0.1 \%)$ & $(0.8 \%)$ & $(0.9 \%)$ \\
\hline THYROID DISORDERS & - & 19 & 19 \\
& & $(1.9 \%)$ & $(1.9 \%)$ \\
\hline SCIATICA & 1 & 34 & 35 \\
& $(0.1 \%)$ & $(3.4 \%)$ & $(3.5 \%)$ \\
\hline NECK PAIN & 2 & 5 & 7 \\
& $(0.2 \%)$ & $(0.5 \%)$ & $(0.7 \%)$ \\
\hline MUSCLE CRAMPS & 1 & 9 & 10 \\
& $(0.1 \%)$ & $(0.9 \%)$ & $(1 \%)$ \\
\hline SINUSITIS & 1 & 3 & 4 \\
& $(0.1 \%)$ & $(0.3 \%)$ & $(0.4 \%)$ \\
\hline ANXIETY DISORDERS & 10 & 68 & 78 \\
& $(1 \%)$ & $(6.8 \%)$ & $(7.8 \%)$ \\
\hline
\end{tabular}

In our study, typical migraine was found in $21.6 \%$ and atypical migraine was found in $78.4 \%$. Our study was similar to Tobias Kurth (2020) in which, 5.2\% were atypical and $94.8 \%$ were typical migraine subjects. 
Table 4: Migraine Type

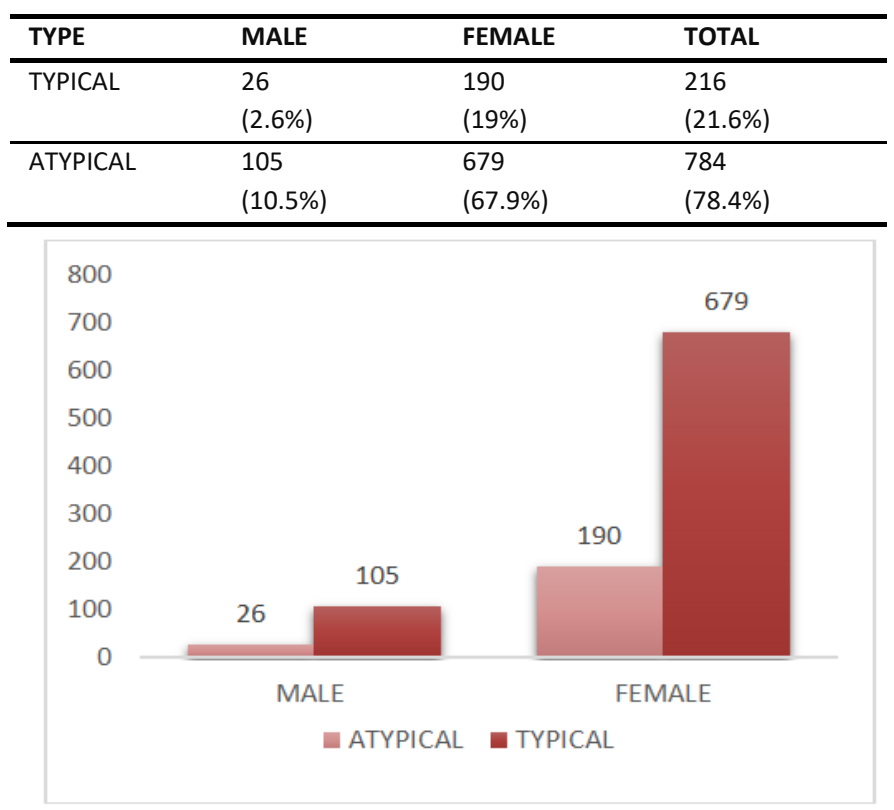

In our study, medication compliance was found in $10.9 \%$ and medication non-compliance was found in $21.1 \%$.

Table 5: Medication adherence

\begin{tabular}{lll}
\hline GENDER & MEDICATION INCOMPLIANCE & REGULAR MEDICATION \\
\hline MALE & $24(2.4 \%)$ & $9(0.9 \%)$ \\
\hline FEMALE & $187(18.7 \%)$ & $100(10 \%)$ \\
\hline TOTAL & $211(21.1 \%)$ & $109(10.9 \%)$ \\
\hline
\end{tabular}

In our study, acute treatment (triptans) history was taken, in which 0-3 drugs taken in a month were 9.9\%. 4-6 drugs taken in a month were $19.5 \%$ and $7-10$ drugs taken in a month were $11.3 \%$.

Table 6: Acute treatment

\begin{tabular}{|c|c|c|c|c|}
\hline $\begin{array}{l}\text { RIZATRIPTAN } \\
\text { NAPROXEN-D }\end{array}$ & $\&$ & 0-3 Drugs & 4-6 Drugs & 7-10 Drugs \\
\hline MALE & & $\begin{array}{l}13 \\
(1.3 \%) \\
\end{array}$ & $\begin{array}{l}18 \\
(1.8 \%) \\
\end{array}$ & $\begin{array}{l}16 \\
(1.6 \%) \\
\end{array}$ \\
\hline FEMALE & & $\begin{array}{l}86 \\
(8.6 \%) \\
\end{array}$ & $\begin{array}{l}177 \\
(17.7 \%) \\
\end{array}$ & $\begin{array}{l}97 \\
(9.7 \%) \\
\end{array}$ \\
\hline TOTAL & & $\begin{array}{l}99 \\
(9.9 \%)\end{array}$ & $\begin{array}{l}195 \\
(19.5 \%)\end{array}$ & $113(11.3 \%)$ \\
\hline
\end{tabular}

In our study, we have taken 2 types of treatment patterns which include FPANR and DPANR. In which, FPANR were $85.1 \%$ and DPANR were $14.9 \%$.

Table 7: Treatment pattern

\begin{tabular}{lll}
\hline DRUGS & FPANR & DPANR \\
\hline MALE & $109(10.9 \%)$ & $21(2.1 \%)$ \\
\hline FEMALE & $742(74.2 \%)$ & $128(12.8 \%)$ \\
\hline TOTAL & $851(85.1 \%)$ & $149(14.9 \%)$ \\
\hline
\end{tabular}

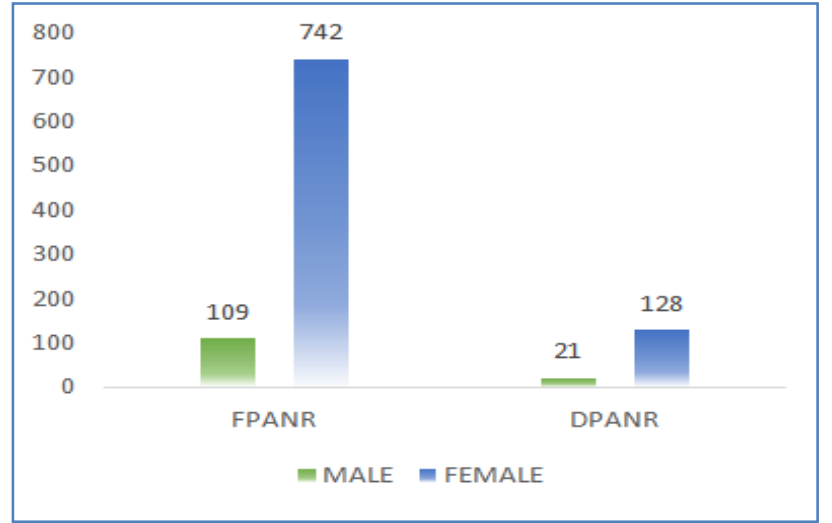

This tool was used to know the severity of migraine (which can be known by the pointing 0 as no pain,1-3 as mild pain, 4-6 as moderate pain, 7-9 as severe pain \& 10 as worst pain). In which mild were $3.5 \%$, moderate were $61.9 \%$, severe were $31.5 \%$, worst were $2.6 \%$ \& no pain were $0.5 \%$. 3 of 1000 were with Refractory Migraine.

Table 8: Pain scale

\begin{tabular}{llllll}
\hline $\begin{array}{l}\text { PAIN } \\
\text { SCALE }\end{array}$ & MILD & MODERATE & SEVERE & WORST & $\begin{array}{l}\text { NO } \\
\text { PAIN }\end{array}$ \\
\hline MALE & $4(0.4 \%)$ & $81(8.1 \%)$ & $42(4.2 \%)$ & $1(0.1 \%)$ & $2(0.2 \%)$ \\
\hline FEMALE & $31(3.1 \%)$ & $538(53.8 \%)$ & $273(27.3 \%)$ & $25(2.5 \%)$ & $3(0.3 \%)$ \\
\hline TOTAL & $35(3.5 \%)$ & $619(61.9 \%)$ & $315(31.5 \%)$ & $26(2.6 \%)$ & $5(0.5 \%)$ \\
\hline
\end{tabular}

Statistical methods:

Chi-Square test \& Odd's ratio were done for type of migraine and the values were found to be $0.2735 \& 0.8849$ respectively with $95 \%$ confidence interval of value 0.559 1.4. Odd's ratio and Chi-Square were also done for treatment pattern and the values were found to be 0.8954 with $95 \%$ confidence interval with value $0.54-1.4 \& 0.1853$ respectively.

\section{Discussion}

Migraine is a condition, which is easily taken now-a-days mostly affecting the quality of life of the individual. Most of the recurrent episodes of migraine were due to medication non-compliance. This study provides the exact treatment pattern in both prophylaxis and acute attacks of migraine and also co-morbidities taking into consideration. In six months study, treatment pattern was analyzed based on the patient's response among 1000 samples.

1. GENDER: Of total study population, female (86.9\%) were predominant over male (13.1\%). Our results are similar to the study conducted by Yohannes W. Woldeamanuel, (2017)(3) where in among 6million patients, $52.4 \%$ were female $\& 47.6 \%$ were male. This could be due to hormonal fluctuations (mainly estrogen) \& unhealthy life style changes (missed/ skipped timings of food \& sleep).

2. AGE: The mean age of our study population was 41.9 years. In our study, the prevalence of migraine is low in 
early old age people $50-65$ years age group ( $23.4 \%$ in which female were $19.9 \%$ \& male were $3.5 \%$ ); $24.1 \%$ ( $20 \%$ were female $\& 4.1 \%$ were male) in $12-30$ years age group and $52.5 \%$ (47\% were female \& $5.5 \%$ were male) in $31-50$ years. Our results are similar to the study conducted by Andreas Straube (2019)(4) where the migraine prevalence was highest for age 31-49yrs (20.1\%) \& declined with age after 60yrs (3.1\%). This could be due to hormonal changes in peri-menopause phase in women mainly, social status, decreased sleep.

3. COMORBIDITIES: In our study, $41.5 \%$ are with different underlying co-morbidities in which stroke were $0.9 \%$, MAV were $1.4 \%$, hypertension were $8.8 \%$, depression were $0.4 \%$, diabetes were $2.6 \%$, epilepsy were $0.9 \%$, thyroid disorder were $1.9 \%$, sinusitis were $0.4 \%$, anxiety disorders were $7.8 \%$ \& somatic symptoms were $16.4 \%$ LBA were $9 \%$, hemiparesthesia were $2.2 \%$, sciatica were $3.5 \%$, neck pain were $0.7 \%$, muscle cramps were $1 \%$ ) \& $58.5 \%$ are with no underlying co-morbidities.

3.1 HYPERTENSION: In our study, $8.8 \%$ were hypertensive in which $5.6 \%$ were with $>5 y$ rs of hypertensive history with mild uncontrolled blood pressure $(140-160 \mathrm{mmHg}), 2.8 \%$ were with $<1 y r$ of hypertensive history with controlled blood pressure \& $0.4 \%$ were with $1-5 y r s$ of hypertensive history with controlled BP. Our results are similar to the study conducted by Hannah Gardener (2016)(5) where 7\% had controlled hypertension and $41 \%$ had uncontrolled hypertension $\leq 9$ years duration. $23 \%$ uncontrolled hypertension. This may be due to rennin-angiotensin system, which is certainly involved in hypertension and has activities in the CNS that may be relevant for migraine. In addition to their action on angiotensin-converting system, they alter sympathetic activity, inhibit free radical activity, increase prostacyclin synthesis and block the degradation of bradykinin, encephalin and substance P. The positive effect can be achieved by regularly monitoring blood pressure and being on regular medication(6).

3.2 DIABETES MELLITUS: In our study, diabetic subjects were $2.6 \%$. In which, almost $2 \%$ has greater than 6 years of diabetic history and $0.6 \%$ has $1-6$ years of diabetic history. Our study was similar to Fatemeh Sadat Haghighi (2016)(7), in which, prevalence of migraine is higher in $>6$ years of diabetic history (33.3\%) than $<6$ years (25.9\%). Migraine can be triggered by nutritional, hormonal or metabolic cause in some individuals which might be the reason for the association of DM in migraine. Hypoglycemia has long been known to be a precipitating factor in migraine onset. An association between polymorphisms in insulin receptor gene and migraine, an elevation in free fatty acid plasma concentration and ketone bodies has also been reported before a migraine attack. Therefore, fasting could promote the development of migraine mostly by favoring hypoglycemia and increased ketone bodies production. In addition, other mechanisms may be involved: CGRP, a neuro peptide expressed in sensory nerves, which seems to play an important role in migraine pathophysiology. Association between CGRP and glucose homeostasis is complex and bi-directional. Positive effect can be achieved by perfect glycemic control(8).

3.3 ANXIETY DISORDERS AND DEPRESSION: In our study, anxiety and depression subjects were combinedly $8.2 \%$ of which $7.8 \%$ were anxiety disorders and $0.4 \%$ were depression subjects. Almost whole percentage of mood disorders were seen in 30-50 years age group. Our study was similar to K. Rammohan (2019)(9). in which, $16.54 \%$ were anxiety disorders and $9.02 \%$ were depression subjects. It is considered that the alteration in expression of sex hormones exerts an effect in both diseases. Changes in ovarian hormones, particularly estrogen drop can lead to down regulation of the sympathetic system which lead to psychiatric migraine comorbidity. Effects and mechanisms of sex hormones in migraine and depression are complex and may involve more than one hormone(10). It may be also due to negative balance between stress and activities.

4. MIGRIANE TYPE: In our study, typical migraine was found in $21.6 \%$ and atypical migraine was found in $78.4 \%$. Our study was similar to Tobias Kurth (2020)(11), in which, $5.2 \%$ were atypical and $94.8 \%$ were typical migraine subjects. It may be due to electrical signals which are responsible for vision that slowly spreads from one area to other of the brain which causes irregular brain activity including irregular blood flow. These all disturbances which are called as cortical spreading depression which impacts the occipital lobe responsible for vision.

5. MEDICATION ADHERENCE: In our study, medication compliance was found in $10.9 \%$ and medication noncompliance was found in $21.1 \%$. Our study was similar to Zsolt Hepp (2015)(12), in which, 26\% were having medication adherence and $50 \%$ were having medication non adherence in over 6 months period. It may be due to socio economic problems, forgetfulness, doubting of a medication's effectiveness, fear of adverse effects and interactions, and mistrust of prescriber. Positive effect can be achieved by proper patient counselling about drugs and their effects.

6. ACUTE TREATMENT: In our study, acute treatment (triptans) history was taken, in which 0-3 drugs taken in a month were 9.9\%. 4-6 drugs taken in a month were $19.5 \%$ and 7-10 drugs taken in a month were $11.3 \%$. This could be due to exposure to triggering factors. Positive effect can be achieved by proper patient counselling about triggering factors such as light, sound, smell, stress and some types of foods like groundnut, tamarind, dairy products, cool beverages etc. 
7. TREATMENT PATTERN: In our study, 2 types of treatment patterns were included i.e; FPANR and DPANR. In which, FPANR were $85.1 \%$ and DPANR were $14.9 \%$. DPANR was suggested only to the patient who does not respond to Flunarizine which may be due to medication non adherence for more than 3 months and severity of headache. Positive effect can be achieved by strict medication adherence.

8. PAIN SCALE TOOL: This tool was used to know the severity of migraine (which can be known by the pointing 0 as no pain,1-3 as mild pain, 4-6 as moderate pain, 7-9 as severe pain \& 10 as worst pain). In which mild were $3.5 \%$, moderate was $61.9 \%$, severe were $31.5 \%$, worst were $2.6 \%$ \& no pain were $0.5 \%$. 3 of 1000 were with Refractory Migraine. It could be due to poor medication adherence, severe exposure to triggering factor. Refractory migraine may be having its end by the new innovation of the migraine drugs which are C-GRP antagonists (Erenumab, Fremanezumab, Galcanezumab, Eptinezumab).

\section{Conclusion}

In our study we found female ratio was high compared to male and was significantly high in age group 31-50 which might be due to skipped breakfasts, fasting, hormonal imbalances, stress. In our study, hypertension was most common comorbid illness followed by GAD. Medication adherence was found to be very low which might be the major factor for recurrent migraine and response to treatment. Although on prophylactic treatment, by evaluating the acute treatment patterns, exposure to different triggering factors can be assessed. Based on the findings from the study, medication adherence was very important to recover quickly from the condition and nonpharmacological measures to be taken to relieve quickly by staying away from triggering factors. Clinical pharmacist plays an important role in treatment and management of headache disorders. Clinical pharmacists can use their expert knowledge of medication and diagnostic criteria and etiology to provide appropriate pharmacotherapy. They can also provide insight and patient counselling to help prevent or reduce the risk of medication overuse and educating them on medication adherence, triggering factors, and acute treatment.

\section{Acknowledgments:}

All the patients are appreciated for their kind co-operation.
Abbreviations:
DM: Diabetes Mellitus
HT: Hypothyroidism
HTN: Hypertension

LBA: Lower Back Ache

MAV: Migraine Associated Vertigo

NSAIDS: Non-Steroidal Anti-Inflammatory Drugs

FPANR: Flunarazine, Propranolol, Amitriptyline, Naproxen, Rizatriptan

DPANR: Divalproate sodium, Propranolol, Amitriptyline, Naproxen, Rizatriptan

\section{GAD: Generalized Anxiety Disorder}

\section{References}

1. A text book of HARRISON'S MANUAL OF MEDICINE, $19^{\text {th }}$ edition, Denis L. Kasper, Anthony S Fauci, Stephen L Hause, New York: Mc Graw Hill Education Medical (215-218), 2016, ISBN 0071828524.

2. A journal of THE AMERICAN SOCIETY POSITION STATEMENT ON INTEGRATING NEW MIGRAINE TREATMENTS INTO CLINICAL PRACTICE, published by Wiley periodicals, 2019 inc. ISSN 00178748, doi:10.10.1111/head.13456.

3. A journal of MIGRAINE AFFECTS 1 IN 10 PEOPLE WORLDWIDE FEATURING RECENT RISE: A SYTEMIC REVIEW AND META- ANALYSIS OF COMMUNITY- BASED STUDIES INVOLVING 6 MILLION PARTICIPANTS, published by Yohannes W Woldeamanuel et al. J Neurol Sci. 2017, PMID: 28017235, DOI: 10. 1016/j.jns.2016.11.071.

4. A journal of PRIMARY HEADACHES DURING LIFESPAN (Journal Of Headache And Pain 20, 35), published by Andreas Straube \& Anna Andreou, 2019, DOI: https://doi.org/10.1186/s10194-019-0985-0.

5. A journal of HYPERTENSION AND MIGRAINE IN THE NORTHERN MANHATTAN STUDY by Hannah Gardener, Teshamae Monteith, Tatijana Rundek, Clinton B. Wright, Mitchell S.V. Elkind and Ralph L. Sacco. Ethn Dis. 2016; 26(3): 323-330. DOI: 10.18865/ed.26.3.323, PMID: 27440971.

6. A journal of NEUROLOGY AND NEURO-SCIENCE: BLOOD PRESSURE CHANGES IN PATIENTS WITH MIGRAINE: EVIDENCES, CONTROVERSIAL VIEWS AND POTENTIAL MECHANISMS OF COMORBIDITY by Sherifa Ahmed Hamed (M.D.), Department of Neurology and Psychiatry, Assiut University Hospital, Egypt. 2010, Vol.1, No. 2:2, : 10:3823/306.

7. A journal of MIGRAINE AND TYPE 2 DIABETES; IS THERE ANY ASSOCIATION? (Journal Of Diabetes And Metabolic Disorders), published by Fatemeh Sadat Haghighi, Nasim Namiranian, Farzane Dehghan, Fahime Chavoshzade and Fariba Seperi, 2016, PMID: 27617234, DOI: 10.1186/s40200-016-0241-y.

8. A journal of METABOLIC SYNDROME AND MIGRAINE by Amit Sachdev and Michael J. Marmura, 2012, PMID: PMC3500825, DOI: 10.3389/fneur.2012.00161.

9. A journal of MIGRAINE AND MOOD DISORDERS: PREVALENCE, CLINICAL CORRELATIONS AND DISABILITY by K. Rammohan, Shyma Manikkoth Mundayadan, 2019, PMID: PMC6337984, DOI: 10.4103/jnrp.jnrp_146_18.

10. A journal of THE EXPLORATION OF MECHANISMS OF COMORBIDITY BETWEEN MIGRAINE AND DEPRESSION by Quin Zhang, Huitzong Tsai and Weibo Liu, 2019, PMID: 31106971, DOI: 10.1111/jcmm.14390.

11. A journal of ASSOCIATION OF MIGRAINE WITH AURA AND OTHER RISK FACTORS WITH INCIDENT CARDIOVASCULAR DISEASE IN WOMEN by Tobias Kurth et al. JAMA.2020;323(22):2281-2289, DOI: 10.1001/jama.2020.7172.

12. A journal of ADHERENCE TO ORAL MIGRAINE- PREVENTIVE MEDICATIONS AMONG PATIENTS WITH CHRONIC MIGRAINE bY Zsolt Hepp et al. Cephalalgia. 2015;35(6):478-88. DOI: 10.1177/0333102414547138. 